УДК 615.322:547.6+543.544

\title{
ДИНАМИКА НАКОПЛЕНИЯ ФЛАВОНОИДОВ В ЛИСТЬЯХ АMARANTHUS RETROFLEXUS, AGASTACHE RUGOSA И THLASPI ARVENSE, СОБРАННЫХ В ЦЕНТРАЛЬНОЙ ЯКУТИИ
}

\author{
() И.В. Слепцов", А.Н. Журавская \\ Институт биологических проблем криолитозоны СО РАН, пр. Ленина, 41, \\ Якутск, 677980 (Россия), e-mail: neroxasg@mail.ru
}

\begin{abstract}
В работе исследовалось изменение содержания флавоноидов в листьях Amaranthus retroflexus, Agastache rugosa и Thlaspi arvense, собранных на территории Центральной Якутии в различные фенологические фазы. Установлено, что в листьях Amaranthus retroflexus, собранного в Центральной Якутии, содержится рутин, в листьях Agastache rugosaлютеолин-7-О-гликозид, апигенин-7-О-гликозид, лютеолин и апигенин, а в листьях Thlaspi arvense - лютеолин-7-Огликозид. Показано, что наибольшее содержание рутина в листьях Amaranthus retroflexus приходилось на фазу цветения. Выявлено, что максимальная концентрация лютеолин-7-О-гликозида, лютеолина и апигенина в листьях Agastache rugosa наблюдалась в период бутонизации и цветения, а апигенин-7-О-гликозида - в фазу цветения. Содержание лютеолин-7-О-гликозида в листьях Thlaspi arvense было наибольшим во время бутонизации и цветения. Таким образом, для получения растительного материала с максимальным содержанием флавоноидов у Amaranthus retroflexus, Agastache rugosa, Thlaspi arvense, выросших на территории Центральной Якутии, сбор следует проводить в период цветения.

Ключевые слова: Amaranthus retroflexus, Agastache rugosa, Thlaspi arvense, флавоноиды, Центральная Якутия, ВЭЖХ, хроматография, фенологические фазы.
\end{abstract}

Работа выполнена в рамках НИР VI.56.1.5. «Физиолого-биохимические механизмы формирования адаптивного потенциала, устойчивости и продуктивности растительных компонентов экосистем Южной и Центральной Якутии» (№ госрегистращии - 01201282194).

\section{Введение}

Флавоноиды - это вторичные метаболиты растений, обладающие антиоксидантными свойствами [1]. Они играют важную роль в метаболизме растений и принимают участие в их развитии и росте [2]. Известно, что содержание биологически активных веществ (БАВ) в растениях зависит от фенологической фазы, абиотических и антропогенных факторов [3, 4]. В результате адаптации растительных организмов к условиям криолитозоны, в том числе к короткому вегетационному сезону, в тканях дикорастущих растений Якутии увеличивается содержание БАВ [5]. Изучение динамики накопления флавоноидов в растениях в течение вегетационного периода является актуальным для выявления роли флавоноидов в развитии и росте растений, а также для определения времени сбора с максимальным их содержанием. Подобные исследования по выявлению изменения качественного состава и концентрации флавоноидов в листьях Amaranthus retroflexus, Agastache rugosa и Thlaspi arvense, собранных на территории Центральной Якутии, ранее не проводились.

Цель работы - изучить динамику накопления флавоноидов в листьях Amaranthus retroflexus, Agastache rugosa и Thlaspi arvense, собранных в Центральной Якутии, в различные фенологические фазы.

\section{Экспериментальная часть}

Слепцов Игорь Витальевич - аспирант,

e-mail: neroxasg@mail.ru

Журавская Алла Николаевна - доктор биологических наук, профессор, главный научный сотрудник, e-mail:jan43@mail.ru
В работе использовались растения Amaranthus retroflexus L. (семейство Amaranthaceae Juss.), Agastache rugosa (Fisch. \& C.A.Mey.) Kuntze (семейство Lamiaceae Martinov) и Thlaspi arvense L. (семейство Brassicaceae Burnett).

\footnotetext{
* Автор, с которым следует вести переписку.
} 
Amaranthus retroflexus и Thlaspi arvense являются однолетними, дикорастущими, травянистыми растениями, широко распространенными на территории Центральной Якутии. Agastache rugosa- многолетнее дикорастущее травянистое растение, произрастающее в Восточной Азии. Amaranthus retroflexus используется в народной медицине при болезнях желудочно-кишечного тракта, печени и желудочного пузыря. Thlaspi arvense применяют в народной медицине как антигистаминное, ранозаживляющее и противомикробное средство. Agastache rugosa широко используют в традиционной китайской медицине как иммуностимулятор, седативное и противовоспалительное средство.

Семена растений высевали в открытый грунт в конце мая на территории Ботанического сада Института биологических проблем криолитозоны СО РАН (Якутск). Отбор листьев исследуемых растений проводили в 10 часов, с 30 июня по 4 августа с интервалом в одну неделю.

Воздушно-сухое сырье экстрагировали метанолом (J.T. Baker) в соотношении 1 : 10, в течение 1 дня, при постоянном перемешивании, в комнатных условиях, после чего полученные экстракты пропускали через мембранный фильтр с диаметром пор 0,20 мкм. Определение содержания флавоноидов в метанольных экстрактах осуществляли методом ВЭЖХ на микроколоночном хроматографе Милихром А-02 фирмы «ЭкоНова» (Россия) с последующей компьютерной обработкой результатов исследования, используя программу «Мулити-Хром» для «Windows».

Разделение проводили по усовершенствованной методике [6] в целях более полного разделения 8 флавоноидов на хроматографической колонке ProntoSIL 120-5-C18 AQ (Россия) размером 2×75 мм. Оптимальное разделение соединений было достигнуто при следующих условиях: подвижная фаза элюент А 1\%-ный водный раствор уксусной кислоты (Panreac AppliChem); В - метанол (J.T. Baker), в градиентном режиме элюирования с возрастанием доли В от 5 до 30\% в течение 2 мин, от 30 до 45\% - в течение 16 мин, от 45 до 55\% - в течение 5 мин и от 55 до $65 \%$ - в течение 7 мин при скорости потока 100 мкл/мин и температуре колонки $40{ }^{\circ} \mathrm{C}$. Общее время анализа занимало 30 мин. Объем проб, вводимых в колонку, составлял 4 мкл. Детектирование проводили с помощью УФ-спектрофотометрического детектора при длинах волн 260, 280, 300, 320, 340 и 360 нм.

В качестве стандартных образцов использовали рутин, апигенин-7-О-гликозид, лютеолин-7-Огликозид, кверцетин, дигидрокверцетин, лютеолин, апигенин и наригенин производства Sigma-Aldrich. Смесь растворов стандартных образцов готовили в концентрациях 6,25, 12,5, 25,0, 50,0, 100,0 мкг/мл в метаноле. В качестве градуировочных зависимостей использовали уравнения линейной регрессии, связывающие концентрации характеризуемых соединений и площади пиков.

Эксперимент выполнялся в трех биологических и в трех аналитических повторностях. Результаты представлены в виде средней арифметической величины. Статистический разброс определяли с использованием доверительного интервала по критерию Стьюдента [7].

\section{Обсуждение результатов}

Как указывалось выше, флавоноиды участвуют в процессах роста и развития растения [2]. Вследствие этого их содержание в различные фенологические фазы варьирует. Считается, что максимальное количество флавоноидов наблюдается в фазы бутонизации и цветения [8, 9]. В работе [10] показано, что некоторые соединения флавоноидного ряда имеют наибольшее содержание не только во время бутонизации и цветения, но и в другие фенологические фазы. Также известно, что фенологическая фаза, в которой содержание флавоноидов максимально, может зависеть от места произрастания [10, 11]. Это может быть связано с адаптацией растения к климатическим условиям региона.

Основными флавоноидами в Amaranthus retroflexus является рутин и кверцетин [12]. В листьях Amaranthus retroflexus, произрастающей в Центральной Якутии, мы обнаружили только рутин, что может быть обусловлено условиями произрастания.

На рисунке 1 показано, что в период вегетации и на начальном этапе бутонизации (с 30 июня по 7 июля) концентрация рутина в листьях Amaranthus retroflexus варьировала от 1,2 до 2,4 мг/г. В фазе бутонизации (с 14 по 28 июля) содержание рутина в листьях составляло от 6,9 до 10,0 мг/г. С 4 августа началось цветение и концентрация рутина в листьях растений повысилась до 16,3 мг/г. Таким образом, максимальное содержание рутина в листьях Amaranthus retroflexus приходилось на фазу цветения.

Известно, что Agastache rugosa содержит семь флавоноидов, четыре из которых являются гликозидами: лютеолин-7-О-, апигенин-7-О-, диосметин-7-О- и акацетин-7-О-гликозид и три агликона: лютеолин, апигенин и акацетин [13]. В листьях Agastache rugosa нами было обнаружено четыре флавоноида: лютеолин-7-О-гликозид, апигенин-7-О-гликозид, лютеолин и апигенин. 
В фазе вегетации (с 30 июня по 14 июля) содержание лютеолин-7-О-гликозид в листьях Agastache rugosa варьировало от 0,06 до 0,11 мг/г, а лютеолина - от 0,54 до 0,66 мг/г. Во время бутонизации и цветения (с 21 июля по 4 августа) в листьях Agastache rugosa концентрация лютеолин-7-О-гликозид статистически достоверно не отличалась и варьировала от 0,25 до 0,28 мг/г. Такая же тенденция наблюдалась и в отношении лютеолина, содержание которого изменялось от 2,5 до 2,8 мг/г (рис. 2).

Содержание апигенин-7-О-гликозида в листьях Agastache rugosa в фазе вегетации (с 30 июня по 14 июля) варьировало от 0,36 до 0,46 мг/г, а апигенина - от 0,51 до 0,58 мг/г. Во время бутонизации (21 июля) в листьях Agastache rugosa содержание апигенин-7-О-гликозида было 0,64 мг/г, а в период цветения (с 28 июля по 4 августа) увеличилось от 0,79 до 1,25 мг/г. Концентрация апигенина в листьях Agastache rugosa во время бутонизации и цветения (с 21 июля по 4 августа) статистически достоверно не изменялась и варьировала от 0,70 до 0,78 мг/г (рис. 3).

Таким образом, максимальное содержание всех изученных нами флавоноидов в листьях Agastache rugosa приходится на период бутонизации и цветения, за исключением апигенин-7-О-гликозида, наибольшая концентрация которого наблюдалась в фазе цветения.

Известно, что в Thlaspi arvense содержится лютеолин-7-гликозид и апигенин-7-гликозид [14]. Но нами в листьях был обнаружен только лютеолин-7-гликозид, что может быть обусловлено условиями произрастания растения.

В фазе вегетации (с 30 июня по 7 июля) содержание лютеолин-7-гликозида в листьях Thlaspi arvense варьировало от 0,08 до 0,09 мг/г, а в период бутонизации и цветения (с 14 по 21 июля) увеличилось до 0,11 мг/г. Вместе с тем в фазе плодоношения (с 28 июля по 4 августа) оно уменьшилось до 0,10 мг/г (рис. 4). Таким образом, в период бутонизации и цветения содержание лютеолин-7-гликозида в листьях Thlaspi arvense было максимальным.

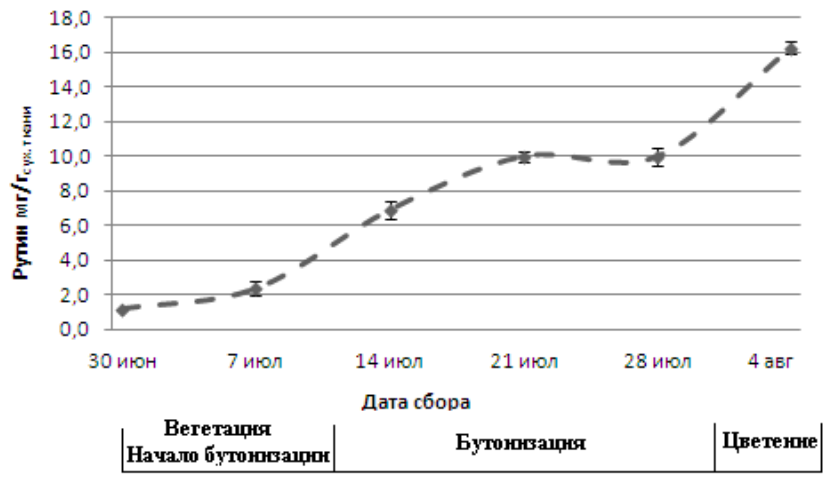

Рис. 1. Динамика накопления рутина в листьях Amaranthus retroflexus в различные фенологические фазы

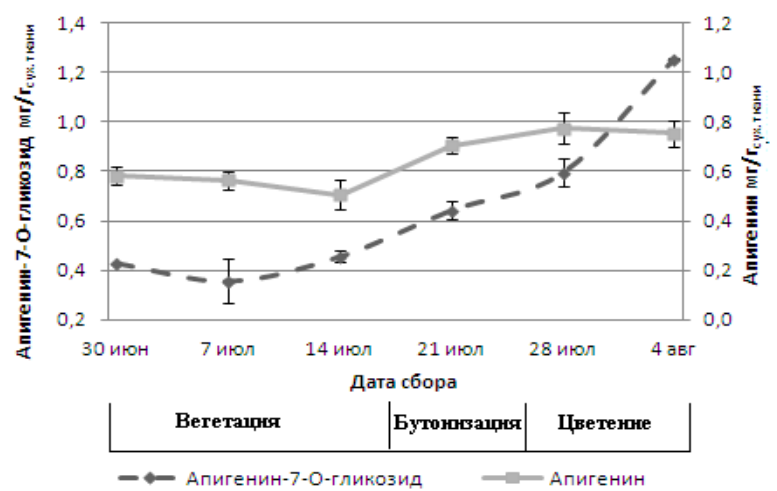

Рис. 3. Динамика накопления апигенин-7гликозида и апигенина в листьях Agastache rugosa в различные фенологические фазы

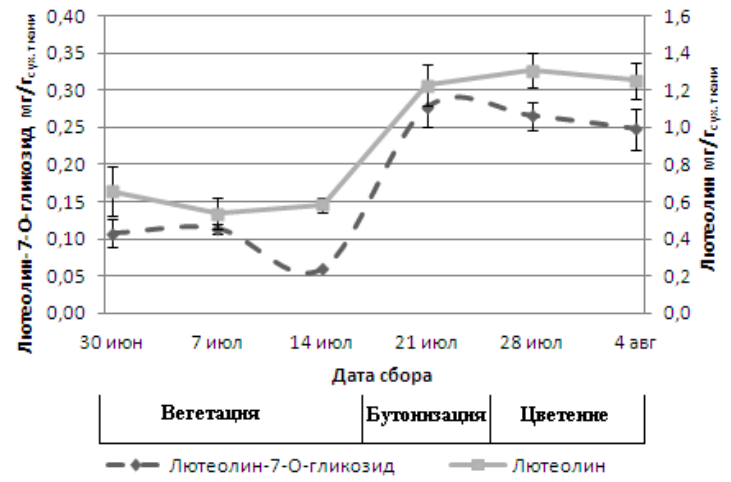

Рис. 2. Динамика накопления лютеолин-7гликозида и лютеолина в листьях Agastache rugosa в различные фенологические фазы

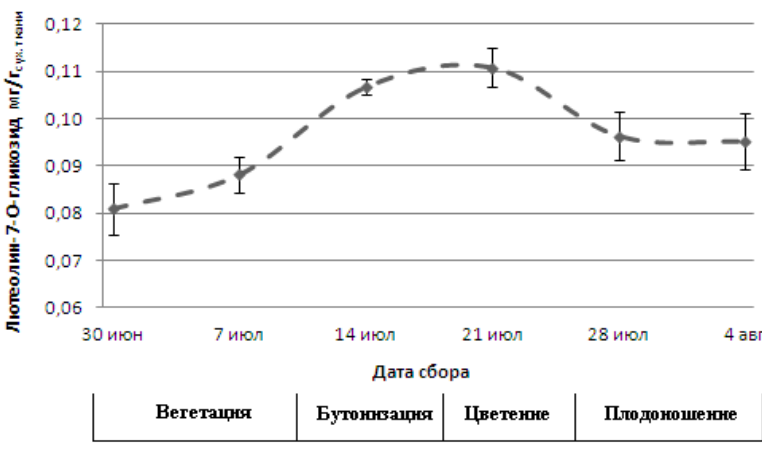

Рис. 4. Динамика накопления лютеолин-7гликозида в листьях Thlaspi arvense в различные фенологические фазы 
По результатам исследования установлено, что максимальное содержание рутина в листьях Amaranthus retroflexus было в фазе цветения; лютеолин-7-О-гликозида, лютеолина и апигенина в листьях Agastache rugosa - в период бутонизации и цветения, апигенин-7-О-гликозида - в фазе цветения; лютеолин-7-О-гликозида в листьях Thlaspi arvense - во время бутонизации и цветения. Это согласуется с исследованиями ряда авторов на примере других видов, где показано, что наибольше содержание флавоноидов приходится на фазы цветения и плодоношения [8, 9].

Это может быть обусловлено тем, что флавоноиды необходимы для привлечения насекомых для опыления [15] и образования пыльцевой трубки [16]. Благодаря этому, возможно, начинается повышенный синтез флавоноидов во всем растении. Также высокое содержание флавоноидов может быть связано с их защитными функциями, и необходимо для выживания растения на таких важных стадиях развития, как бутонизация и цветение, так как известно, что флавоноиды защищают растения от травоядных насекомых, патогенных бактерий и грибков [17-19].

\section{Выводы}

Изучено изменение содержания некоторых флавоноидов в различные фенологические фазы в листьях Amaranthus retroflexus, Agastache rugosa, Thlaspi arvense, собранных в условиях криолитозоны Центральной Якутии. Установлено, что в листьях Amaranthus retroflexus содержится рутин, в листьях Agastache rugosa - лютеолин-7-О-гликозид, апигенин-7-О-гликозид, лютеолин и апигенин, в листьях Thlaspi arvense - лютеолин-7-О-гликозид. Показано, что в листьях Amaranthus retroflexus наибольшее содержание рутина приходилось на фазу цветения. Выявлено, что максимальная концентрация лютеолин-7О-гликозида, лютеолина и апигенина в листьях Agastache rugosa наблюдалась в период бутонизации и цветения, апигенин-7-О-гликозида - в фазе цветения. Содержание лютеолин-7-О-гликозида в листьях Thlaspi arvense было наибольшим во время бутонизации и цветения. Таким образом, для получения растительного материала с максимальным содержанием флавоноидов в листьях Amaranthus retroflexus, Agastache rugosa, Thlaspi arvense, выросших в условиях Центральной Якутии, сбор вегетативной массы следует проводить в период цветения.

\section{Список литературы}

1. Andersen O.M., Markham K.R. Flavonoids: chemistry, biochemistry and applications. CRC Press, 2005. 1256 p.

2. Тараховский Ю.С., Ким Ю.А., Абдрасилов Б.С., Музафаров Е.Н. Флавоноиды: биохимия, биофизика, медицина. Пущино, 2013. $310 \mathrm{c.}$

3. Минаева В.Г. Флавоноиды в онтогенезе растений и их практическое использование. Новосибирск, 1978. $252 \mathrm{c}$.

4. Кершенгольц Б.М. Неспецифические биохимические механизмы адаптации организмов к экстремальным условиям среды // Наука и образование. 1996. Т. 3. С. 130-138.

5. Кершенгольц Б.М. Структурное разнообразие биологически активных веществ - биохимическая основа толерантности организмов в стрессовых условиях среды // Терпимость: идеи и традиции : материалы Международной научной конференции. Якутск, 1995. С. 179-184.

6. Шеин А.А., Прокопьев И.А., Филиппова Г.В., Журавская А.Н. Влияние техногенного загрязнения на содержание фотосинтетических пигментов и флавоноидов Matricaria Chamomila (Asteraceae) // Растительные ресурсы. 2014. №2. С. 235-241.

7. Лакин Г.Ф. Биометрия. М., 1980. 456 с.

8. Ломбоева С.С., Танхаева Л.М., Олейников Д.Н. Динамика накопления флавоноидов в надземной части ортилии однобокой (Orthilia Secunda (L.) House) // Химия растительного сырья. 2008. №3. C. 83-88.

9. Костикова В.А., Высочина Г.И., Петрук А.А. Особенности накопления флавоноидов в органах надземной части Rheum compactum L. // Химия растительного сырья. 2015. №4. С. 147-150.

10. Çurak C., Radušienė J., Janulis V., Ivanauskas L. Secondary metabolites in Hypericum perfoliatum: variation among plant parts and phenological stages // Botanica Helvetica. 2007. Vol. 117. N1. Pp. 29-36.

11. Kazlauskas S., Bagdonaite E. Quantitative analysis of active substances in St. John's wort (Hypericum perforatum L.) by the high performance liquid chromatography method // Medicina. 2003. Vol. 40. N10. Pp. 975-981.

12. Kalinova J., Dadakova E. Rutin and total quercetin content in amaranth (Amaranthus spp.) // Plant foods for human nutrition. 2009. Vol. 64. N1. Pp. 68-74.

13. Vogelmann J.E. Flavonoids of Agastache section Agastache // Biochemical systematics and ecology. 1984. Vol. 12. N4. Pp. 363-366. 
14. Llugany M., Tolrà R., Martín S.R., Poschenrieder C., Barceló J. Cadmium induced changes in glutathione and phenolics of Thlaspi and Noccaea species differing in Cd accumulation // Journal of Plant Nutrition and Soil Science. 2013. Vol. 176. N6. Pp. 851-858.

15. Formica J.V., Regelson W. Review of the biology of quercetin and related bioflavonoids // Food and chemical toxicology. 1995. Vol. 33. N12. Pp. 1061-1080.

16. Минаева В.Г., Горбалева Г.Н. О влиянии флавоноидов на прорастание пыльцы и рост пыльцевых трубок // Полезные растения природной флоры Сибири. Новосибирск, 1967. С. 231-237.

17. Harborne J.B., Williams C.A. Advances in flavonoid research since 1992 // Phytochemistry. 2000. Vol. 55. N6. Pp. 481-504.

18. Dai G.H., Nicole M., Andary C., Martinez C., Bresson E., Boher B., Daniel J.F., Geiger J.P. Flavonoids accumulate in cell walls, middle lamellae and callose-rich papillae during an incompatible interaction between Xanthomonas campestris pv. malvacearum and cotton // Physiological and Molecular Plant Pathology. 1996. Vol. 49. N5. Pp. 285-306.

19. Mierziak J., Kostyn K., Kulma A. Flavonoids as important molecules of plant interactions with the environment // Molecules. 2014. Vol. 19, N10. Pp. 16240-16265.

Поступило в редакцию 8 апреля 2016 г.

После переработки 18 мая 2016 г. 
Sleptsov I.V.*, Zhuravskaia A.N. DYNAMICS OF ACCUMULATIONS IN LEAVES FLAVONOIDS AMARANTHUS RETROFLEXUS, AGASTACHE RUGOSA AND THLASPI ARVENSE GATHERED IN THE CENTRAL YAKUTIA

Institute of Biological Problems Cryolithozone, pr. Lenina, 41, Yakutsk, 677980 (Russia), e-mail: Neroxasg@mail.ru

We investigated changes in the content of flavonoids in the leaves of Amaranthus retroflexus, Agastache rugosa and Thlaspi arvense, gathered in the Central Yakutia in different phenological phases. It is established that in leaves Amaranthus retroflexus, grown in the Central Yakutia contains rutin, in leaves Agastache rugosa - luteolin-7-O-glucoside, apigenin-7-Oglucoside, luteolin and apigenin, and leaves Thlaspi arvense - luteolin-7-O-glycoside. It is shown that the highest content of rutin in leaves Amaranthus retroflexus were in the flowering stage. It was revealed that the maximum concentration of luteolin7-O-glucoside, luteolin and apigenin in leaves Agastache rugosa observed in the period of budding and flowering, and apigenin-7-O-glucoside - in the flowering stage. The content of luteolin-7-O-glucoside in Thlaspi arvense leaves was highest during budding and flowering. Thus, to obtain plant material with a maximum content of flavonoids in Amaranthus retroflexus, Agastache rugosa, Thlaspi arvense grown in Central Yakutia collecting should be carried out in the flowering stage.

Keywords: Amaranthus retroflexus, Agastache rugosa, Thlaspi arvense, flavonoids, Central Yakutia, HPLC, chromatography, phenological phases.

\section{References}

1. Andersen O.M., Markham K.R. Flavonoids: chemistry, biochemistry and applications. CRC Press, 2005. 1256 p.

2. Tarakhovskii Iu.S., Kim Iu.A., Abdrasilov B.S., Muzafarov E.N. Flavonoidy: biokhimiia, biofizika, meditsina. [Flavonoids: biochemistry, biophysics, medicine]. Pushchino, 2013, 310 p. (in Russ.).

3. Minaeva V.G. Flavonoidy v ontogeneze rastenii i ikh prakticheskoe ispol'zovanie. [Flavonoids in plant ontogeny and their practical use]. Novosibirsk, 1978, 252 p. (in Russ.).

4. Kershengol'ts B.M. Nauka i obrazovanie, 1996, vol. 3, pp. 130-138. (in Russ.).

5. Kershengol'ts B.M. Terpimost': idei i traditsii (materialy Mezhduna-rodnoi nauchnoi konferentsii). [Tolerance: the ideas and traditions (proceedings of the International Scientific Conference)]. Iakutsk, 1995, pp. 179-184. (in Russ.).

6. Shein A.A., Prokop'ev I.A., Filippova G.V., Zhuravskaia A.N. Rastitel'nye resursy, 2014, no. 2, pp. 235-241. (in Russ.).

7. Lakin G.F. Biometriia. [Biometrics]. Moscow, 1980, 456 p. (in Russ.).

8. Lomboeva S.S., Tankhaeva L.M., Oleinikov D.N. Khimiia rastitel'nogo syr'ia, 2008, no. 3, pp. 83-88. (in Russ.).

9. Kostikova V.A., Vysochina G.I., Petruk A.A. Khimiia rastitel'nogo syria, 2015, no. 4, pp. 147-150. (in Russ.).

10. Çırak C., Radušienė J., Janulis V., Ivanauskas L. Botanica Helvetica, 2007, vol. 117, no. 1, pp. 29-36.

11. Kazlauskas S., Bagdonaite E. Medicina, 2003, vol. 40, no. 10, pp. 975-981.

12. Kalinova J., Dadakova E. Plant foods for human nutrition, 2009, vol. 64, no. 1, pp. 68-74.

13. Vogelmann J.E. Biochemical systematics and ecology, 1984, vol. 12, no. 4, pp. 363-366.

14. Llugany M., Tolrà R., Martín S.R., Poschenrieder C., Barceló J. Journal of Plant Nutrition and Soil Science, 2013, vol. 176 , no. 6 , pp. $851-858$.

15. Formica J.V., Regelson W. Food and chemical toxicology, 1995, vol. 33, no. 12, pp. 1061-1080.

16. Minaeva V.G., Gorbaleva G.N. Poleznye rasteniia prirodnoi flory Sibiri. [Useful plants of the natural flora of Siberia]. Novosibirsk, 1967, pp. 231-237. (in Russ.).

17. Harborne J.B., Williams C.A. Phytochemistry, 2000, vol. 55, no. 6, pp. 481-504.

18. Dai G.H., Nicole M., Andary C., Martinez C., Bresson E., Boher B., Daniel J.F., Geiger J.P. Physiological and Molecular Plant Pathology, 1996, vol. 49, no. 5, pp. 285-306.

19. Mierziak J., Kostyn K., Kulma A. Molecules, 2014, vol. 19, no. 10, pp. 16240-16265.

Received April 8, 2016

Revised May 18, 2016

\footnotetext{
* Corresponding author.
} 